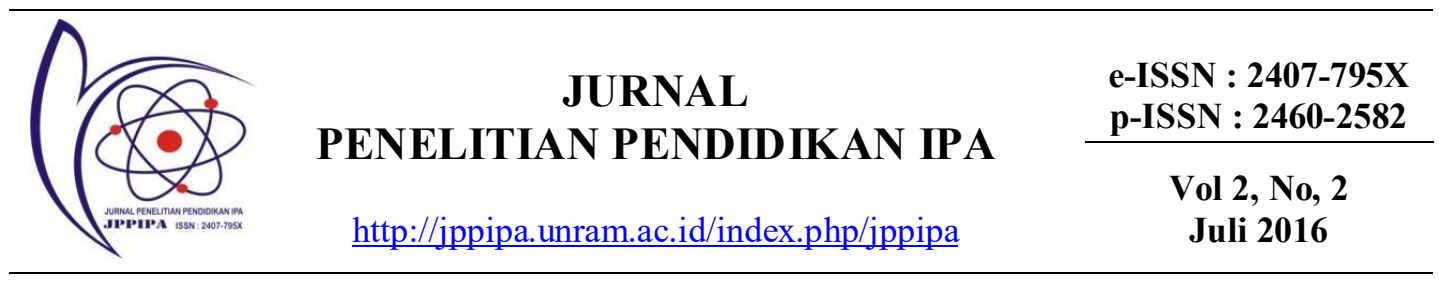

\title{
PENGEMBANGAN MODEL PEMBELAJARAN KOOPERATIF TIPE KOSAJI PADA PEMBELAJARAN FISIKA
}

\author{
Rumansyah $^{1}$, Kosim $^{2}$, Harry Soepriyanto ${ }^{3}$ \\ Program Studi Magister Pendidikan IPA, Program Pascasarjana Universitas Mataram ${ }^{123}$ \\ e-mail: rumansyah2015@yahoo.com
}

\begin{abstract}
\begin{tabular}{|c|c|}
\hline Key Words & Abstract \\
\hline $\begin{array}{l}\text { KOSAJI } \\
\text { Cooperative } \\
\text { Learning } \\
\text { Model, Physics } \\
\text { Learning }\end{array}$ & $\begin{array}{l}\text { This study aims to develop a cooperative learning model of KOSAJI type that valid, practical and effective. KOSAJI of } \\
\text { cooperative learning model is a collaboration between cooperative learning model type STAD and Jigsaw in physics } \\
\text { learning. The method used was the research development model adopted Dick and Carey with ten stages which includes a } \\
\text { needs analysis to determine the objectives, formulate indicators, the analysis of the students and the context, the } \\
\text { establishment of specific goals of learning, the development of assessment tools of learning, the development of learning } \\
\text { strategies, the development and selection of material lesson, formative evaluation, revision of the device, and a summative } \\
\text { evaluation of the effectiveness of the device. This research was conducted at SMAN } 1 \text { Mataram. KOSAJI cooperative } \\
\text { learning model developed together with learning devices such as lesson plans, worksheets, questionnaires students' attitude } \\
\text { towards physical and cognitive achievement test. KOSAJI learning model along with the device has been through expert } \\
\text { validation, test a small group, limited field testing and large-scale (summative evaluation). Implementation KOSAJI } \\
\text { learning model in teaching physics to minimize shortage and optimize the advantages that exist in both the type of } \\
\text { cooperative learning model. Based on expert validator test KOSAJI learning model and is well worth learning device used } \\
\text { with a percentage value of } 94.99 \% \text {. After going through the stages of the test group was small and limited field KOSAJI } \\
\text { learning model can be applied to both in terms of the response of the students ( } 80.52 \% \text { on a small test group and } 83.41 \% \text { in } \\
\text { the limited field testing ), the response of teachers ( } 76.92 \% \text { in the small test group and } 82.69 \% \text { limited field tests) and } \\
\text { enforceability of RPP ( } 86.61 \% \text { on a small group of test and } 86,62 \% \text { in limited field test) with some revisions .Summative } \\
\text { test results showed that the learning model KOSAJI effectively improve students' cognitive learning outcomes with } \\
\text { increased value in terms of pretest and posttest of } 41.93 \% \text {. Therefore, the development of cooperative learning in teaching } \\
\text { physics KOSAJI proved valid, practical and effective. }\end{array}$ \\
\hline
\end{tabular}
\end{abstract}

\begin{tabular}{|c|c|}
\hline Kata Kunci & Abstrak \\
\hline $\begin{array}{l}\text { Model } \\
\text { Kooperatif } \\
\text { Tipe KOSAJI, } \\
\text { Pembelajaran } \\
\text { Fisika }\end{array}$ & $\begin{array}{l}\text { Penelitian ini bertujuan untuk mengembangkan model pembelajaran kooperatif tipe KOSAJI yang valid, praktis dan efektif. } \\
\text { Model pembelajaran kooperatif KOSAJI merupakan kolaborasi antara model pembelajaran kooperatif tipe STAD dan } \\
\text { Jigsaw pada pembelajaran fisika. Metode penelitian yang digunakan adalah penelitian pengembangan yang mengadopsi } \\
\text { model Dick and Carey dengan sepuluh tahapan meliputi analisis kebutuhan untuk menentukan tujuan, merumuskan } \\
\text { indikator, analisis siswa dan konteks, penetapan tujuan khusus pembelajaran, pengembangan perangkat penilaian } \\
\text { pembelajaran, pengembangan model pembelajaran, pengembangan dan pemilihan materi pelajaran, evaluasi formatif, revisi } \\
\text { perangkat, dan evaluasi sumatif terhadap efektivitas perangkat. Penelitian ini dilaksanakan di SMAN } 1 \text { Mataram. Model } \\
\text { pembelajaran kooperatif tipe KOSAJI dikembangkan beserta perangkat pembelajaran berupa RPP, LKS, angket sikap siswa } \\
\text { terhadap fisika dan tes hasil belajar kognitif. Model pembelajaran KOSAJI beserta perangkatnya telah melalui validasi ahli, } \\
\text { uji kelompok kecil, uji lapangan terbatas, dan skala luas (evaluasi sumatif). Implementasi model pembelajaran KOSAJI } \\
\text { pada pembelajaran fisika dapat meminimalisir kekurangan dan mengoptimalkan kelebihan yang ada pada kedua tipe model } \\
\text { pembelajaran kooperatif tersebut. Berdasarkan uji validator ahli model pembelajaran KOSAJI dan perangkat pembelajaran } \\
\text { sangat layak digunakan dengan persentase nilai sebesar } 94,99 \% \text {. Setelah melalui tahapan uji kelompok kecil dan lapangan } \\
\text { terbatas model pembelajaran KOSAJI dapat diterapkan dengan baik ditinjau dari respon siswa ( } 80,52 \% \text { pada uji kelompok } \\
\text { kecil dan } 83,41 \% \text { pada uji lapangan terbatas), respon guru ( } 76,92 \% \text { pada uji kelompok kecil dan } 82,69 \% \text { pada uji lapangan } \\
\text { terbatas) dan keterlaksanaan RPP ( } 86,61 \% \text { pada uji kelompok kecil dan } 86,62 \% \text { pada uji lapangan terbatas) dengan beberapa } \\
\text { revisi. Hasil uji sumatif menunjukkan bahwa model pembelajaran KOSAJI efektif meningkatkan hasil belajar kognitif siswa } \\
\text { dengan nilai peningkatan ditinjau dari pretes dan postes sebesar } 41,93 \% \text {. Oleh karena itu pengembangan pembelajaran } \\
\text { kooperatif tipe KOSAJI pada pembelajaran fisika terbukti valid, praktis dan efektif. }\end{array}$ \\
\hline
\end{tabular}




\section{PENDAHULUAN}

Fisika merupakan salah satu cabang IPA yang mendasari perkembangan teknologi maju dan konsep hidup harmonis dengan alam. Sebagai ilmu yang mempelajari fenomena alam, fisika merupakan materi pelajaran yang memberikan pelajaran yang baik kepada manusia untuk hidup selaras berdasarkan hukum alam. Pada tingkat SMA/MA, fisika di pandang penting untuk diajarkan sebagai mata pelajaran tersendiri dengan beberapa pertimbangan. Pertama, selain memberikan bekal ilmu kepada siswa, pelajaran fisika dimaksudkan sebagai wahana untuk menumbuhkan kemampuan berpikir yang berguna untuk memecahkan masalah di dalam kehidupan sehari-hari. Kedua, mata pelajaran fisika perlu diajarkan untuk tujuan yang lebih khusus yaitu membekali siswa pengetahuan dan pemahaman dan sejumlah kemampuan yang dipersyaratkan untuk memasuki jenjang yang lebih tinggi serta mengembangkan ilmu dan teknologi.

Dalam pembelajaran Fisika selama ini timbul masalah-masalah yang perlu dicari solusinya. Umumnya masalah yang timbul adalah kurang memahami materi yang disampaikan guru. Hal ini dipengaruhi oleh pembelajaran yang masih berpusat pada guru dan kurangnya variasi dalam pembelajaran, sehingga menjadikan siswa kurang aktif dalam mendapatkan pengetahuan. Dilihat dari hal tersebut, maka perlu diusahakan agar pelajaran menjadi lebih menarik, dan tidak membosankan. Guru dituntut pandai dalam menerapkan suatu model pembelajaran yang tepat sesuai dengan karakteristik suatu pokok bahasan, sehingga tujuan pembelajaran dapat tercapai dengan baik.

Salah satu upaya untuk memperbaiki dan meningkatkan hasil belajar siswa di bidang fisika adalah dengan melakukan perbaikan dan inovasi dalam proses pembelajaran fisika di kelas. Upaya perbaikan pembelajaran dilakukan dengan menerapkan model pembelajaran dengan tujuan agar proses pembelajaran lebih terarah dan terukur. Alternatif model pembelajaran yang cocok adalah model pembelajaran kooperatif. Dalam konstruktivisme, siswa secara aktif membangun pengetahuan mereka sendiri dalam proses pembelajaran. Peran guru adalah membantu siswa menemukan fakta, konsep atau prinsip bagi diri mereka sendiri, bukan memberikan ceramah atau mengendalikan seluruh kegiatan kelas (Nur dan Wikandari, 2000). Slavin (2011) menyatakan bahwa siswa akan lebih mudah menemukan dan memahami konsep-konsep yang sulit apabila mereka dapat saling mendiskusikan masalahmasalah itu dengan temannya.

Pembelajaran kooperatif memiliki beragam tipe, di antaranya student teams 
achievement division (STAD) dan tim ahli (Jigsaw). Pembelajaran kooperatif tipe STAD merupakan pembelajaran kooperatif dimana siswa dibagi dalam kelompokkelompok kecil dalam menerima materi dan menyelesaikan tugas-tugas pembelajarannya. Sementara pembelajaran kooperatif tipe Jigsaw adalah pembelajaran kooperatif dimana tiap kelompok memiliki beberapa anggota yang berperan sebagai tim ahli dalam memberi pemahaman pengetahuan kepada anggota tim yang lainnya (Ibrahim dkk., 2000). Adanya pemberian penghargaan kepada kelompok pada STAD dan Jigsaw diasumsikan dapat menumbuhkan suasana menyenangkan bagi siswa (Sanjaya, 2011).

Hasil penelitian Sukiman (2010) yang membandingkan pengaruh pembelajaran sains berbasis inkuiri (PSBI) dengan teknik kooperatif tipe STAD dan Jigsaw terhadap minat, dan hasil belajar, ditemukan adanya pengaruh PSBI dengan teknik STAD dan Jigsaw dalam meningkatkan minat dan hasil belajar siswa. Hal senada juga diungkapkan Arizona (2013) bahwa pembelajaran kooperatif dapat meningkatkan hasil belajar kognitif siswa.

Sebuah model pembelajaran kooperatif telah dikembangkan peneliti yaitu model pembelajaran kooperatif tipe KOSAJI yang merupakan kolaborasi
STAD dan JIGSAW. Implementasi model pembelajaran KOSAJI pada pembelajaran fisika dapat meminimalisir kekurangan dan mengoptimalkan kelebihan yang ada pada kedua tipe model pembelajaran kooperatif tersebut. Berdasarkan hal tersebut penelitian ini bertujuan untuk mengembangkan model pembelajaran kooperatif tipe KOSAJI pada pembelajaran fisika yang valid, praktis, dan efektif.

\section{METODE PENELITIAN}

Jenis penelitian ini merupakan penelitian dan pengembangan (Research and Development atau R\&D). Model pengembangan yang digunakan yaitu mengacu pada model pengembangan Dick \& Carey (2009). Prosedur pengembangan meliputi analisis kebutuhan untuk menentukan tujuan, merumuskan indikator, analisis siswa dan konteks, merumuskan tujuan khusus pembelajaran, mengembangkan perangkat penilaian pembelajaran, mengembangkan materi pembelajaran, merancang dan mengembangkan evaluasi formatif, merevisi perangkat, mengembangkan evaluasi sumatif. Tahapan-tahapan dalam model pengembangan Dick and Carey dapat dilihat pada Gambar 1.

Sasaran penelitian pengembangan yaitu mengembangkan perangkat pembelajaran yang diakhiri dengan uji perangkat, sehingga dalam penelitian ini 
dihasilkan produk perangkat pembelajaran Fisika berupa rencana pelaksanaan pembelajaran (RPP), lembar kerja siswa (LKS), instrumen tes hasil belajar kognitif, dan angket sikap siswa terhadap fisika.

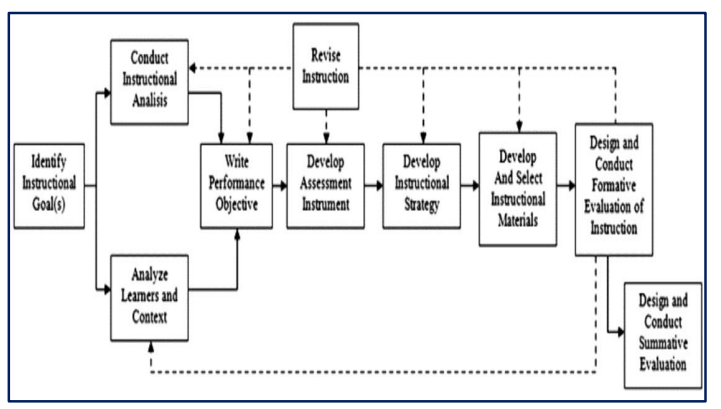

Gambar 1. Model Pengembangan Dick dan Carey (2009)

\section{Evaluasi formatif}

Evaluasi formatif atau uji coba perangkat dilakukan dalam dua tahap yaitu uji ahli atau uji perorangan, uji kelompok kecil, dan uji kelompok terbatas.

\section{a. Uji Ahli}

Uji ahli dilakukan untuk mengetahui kualitas draf awal perangkat (draf I) terutama menyangkut aspek ketatabahasaan, kesesuaian materi dengan indikator pembelajaran, validitas isi, kebenaran konsep, maka draf dievaluasi oleh dosen pembimbing. Selain itu, perangkat pembelajaran dievaluasi juga oleh guru Fisika yang sudah berpengalaman. Hasil evaluasi ahli selanjutnya dianalisis dan dijadikan acuan untuk merevisi draf I dan hasil revisinya disebut draf II. Hasil evaluasi ahli merupakan informasi kualitatif yang diperoleh melalui analisis instrumen penilaian ahli. Dalam memvalidasi, validator ahli diminta untuk memberikan penilaian dan pendapat terhadap perangkat yang digunakan.

\section{b. Uji Kelompok Kecil}

Perangkat pembelajaran (Draft II) selanjutnya diuji cobakan pada kelompok kecil yang berjumlah 16 orang siswa yang diperoleh secara acak. Evaluasi ini bertujuan untuk memperoleh informasi mengenai keterbacaan naskah dan keberlangsungan sintaks yang telah dirancang pada model pembelajaran KOSAJI yang diterapkan. Siswa diminta membaca dan memberikan tanggapan terhadap perangkat pembelajaran yang telah dibuat dengan menggunakan penilaian perangkat oleh siswa. Hasil revisi dari uji kelompok kecil ini (selanjutnya disebut draft III) akan digunakan untuk uji lapangan.

Hasil uji perangkat oleh ahli dan kelompok kecil dilakukan untuk mengetahui kriteria kelayakan perangkat agar dapat dipergunakan dalam pembelajaran. Adapun indikator kelayakan perangkat yang digunakan untuk validasi adalah: 4 = sangat baik, $3=$ baik, $2=$ kurang, dan 1 = sangat kurang. Dalam menentukan skor ideal digunakan rumus: Skor ideal $=$ skor tertinggi $\mathrm{x}$ jumlah butir instrumen 
Sedangkan rumus yang digunakan untuk menentukan Skor perangkat $(\mathrm{N})$ secara keseluruhan adalah:

$$
N=\frac{\sum \text { Skor Perolehan }}{\sum \text { Skor Ideal }} \times 100 \%
$$

Selanjutnya ditentukan rentang nilai $(\mathrm{RN})$ untuk menentukan kriteria perangkat dengan rumus:

$R N=\frac{\sum \text { Skor Ideal-Skor ideal }}{\sum \text { Indikator }}$

\section{c. Uji Kelompok Terbatas}

Pada tahap ini perangkat pembelajaran digunakan oleh guru sebagai media pembelajaran di kelas. Uji ini merupakan langkah terakhir dari evaluasi formatif. Uji kelompok terbatas bertujuan untuk mengetahui efektifitas dan sisi praktis dari penerapan perangkat. Hasil uji ini digunakan untuk mengetahui respon siswa terhadap perangkat pembelajaran dan kegiatan pembelajaran. Selain itu, juga digunakan untuk pengujian instrumen tes hasil belajar kognitif siswa meliputi uji validitas, reliabilitas, indeks kesukaran, dan daya beda soal menggunakan rumusrumus di bawah ini:

\section{1) Validitas}

Untuk mencari validitas tiap butir soal dapat dihitung dengan menggunakan Product Moment Pearson sebagai berikut:

$$
r_{\text {hitung }}=\frac{n \sum X Y-\left(\sum X\right)\left(\sum Y\right)}{\sqrt{\left(n \sum X^{2}-\left(\sum X\right)^{2}\left(n \sum Y^{2}-\left(\sum Y\right)^{2}\right)\right.}}
$$

Keterangan:

$\mathrm{n} \quad=$ Banyaknya peserta tes

$\mathrm{X}=$ Skor tiap item

$\mathrm{Y}=$ Skor Seluruh item responden uji coba

$\mathrm{r}_{\text {hitung }}=$ Koefisien korelasi antara variable $\mathrm{X}$ dan $\mathrm{Y}$

Distribusi (Tabel t) untuk $\alpha=0,05$ dan derajat kebebasan $(\mathrm{dk}=\mathrm{n}-2)$. Kaidah keputusan: Jika $\mathrm{t}_{\text {hitung }}>\mathrm{t}_{\text {tabel }}$ berarti valid, sebaliknya $\quad \mathrm{t}$ hitung $\leq \mathrm{t}$ tabel berarti tidak valid (Sugiyono, 2011). Jika instrumen valid maka dilihat kriteria penafsiran mengenai indeks korelasinya (r). Adapun kriteria yang digunakan menurut Riduwan (2010) sebagai berikut:

1. Antara 0,800 sampai dengan 1,000 : sangat tinggi

2. Antara 0,600 sampai dengan 0,799 : tinggi

3. Antara 0,400 sampai dengan 0,599 : cukup tinggi

4. Antara 0,200 sampai dengan 0,399 : rendah

5. Antara 0,000 sampai dengan 0,199 : sangat rendah (tidak valid)

Setelah harga koefisien validitas tiap butir soal diperoleh, perlu dilakukan uji signifikansi untuk mengukur keberartian koefisien korelasi berdasarkan distribusi kurva normal dengan menggunakan statistik uji-t dengan persamaan:

$$
t=r_{x y} \sqrt{\frac{n-2}{1-r_{x y}^{2}}}
$$

Keterangan:

$\mathrm{t}=$ nilai hitung koefisien validitas

$\mathrm{n}=$ Banyaknya peserta tes 
$\mathrm{x} \quad=$ Skor tiap item

$\mathrm{y}=$ Skor Seluruh item responden uji coba

$\mathrm{r}_{\mathrm{xy}}=$ Koefisien korelasi antara variable $\mathrm{X}$ dan $\mathrm{Y}$

Untuk mengetahui valid atau tidaknya butir soal maka harga thitung dibandingkan dengan $t_{\text {tabel}}$, dengan ketentuan jika $t_{\text {hitung }}>t_{\text {tabel, }}$ maka soal dikatakan valid atau sebaliknya jika $t_{\text {hitung }} \leq$ $\mathrm{t}_{\text {tabel, }}$ maka soal dikatakan tidak valid (Riduwan, 2010).

\section{2) Reliabilitas}

Reliabilitas soal tes, dihitung dengan menggunakan rumus KR-20 (Kuder Richardson), yaitu sebagai berikut:

$$
r_{11}=\left[\frac{k}{k-1}\right]\left[\frac{s^{2}-\sum p q}{s^{2}}\right]
$$

Keterangan:

$$
\begin{array}{ll}
\mathrm{r}_{11} & =\text { koofesien reliabilitas tes internal } \\
& \text { seluruh item } \\
\mathrm{p} & \begin{array}{l}
\text { = proporsi subjek yang menjawab } \\
\text { item dengan benar }
\end{array} \\
\mathrm{q} & \begin{array}{l}
=1-\mathrm{p} \text { (proporsi subjek yang } \\
\text { menjawab item dengan salah) }
\end{array} \\
\sum p q & =\text { jumlah hasil perkalian p dan } \mathrm{q} \\
\mathrm{k} & =\text { jumlah item dalam instrumen } \\
\mathrm{s} & =\text { standar deviasi } \\
\mathrm{s}^{2} & =\text { varians total }
\end{array}
$$

Adapun kriteria reliabilitas soal adalah sebagai berikut:

Tabel 1. Kriteria Nilai Reliabilitas

\begin{tabular}{ccc}
\hline No & Nilai & Kategori \\
\hline $\mathbf{1}$ & $0,81-$ & Sangat \\
& 1,00 & tinggi \\
$\mathbf{2}$ & $0,61-$ & Tinggi \\
& 0,80 & \\
$\mathbf{3}$ & $0,41-$ & Cukup \\
& 0,60 & tinggi \\
\hline
\end{tabular}

\begin{tabular}{ccc}
\hline 4 & $0,21-$ & Rendah \\
& 0,40 & \\
5 & $0,00-$ & Sangat \\
& 0,20 & rendah \\
\hline
\end{tabular}

(Sumber: Arikunto, 2006)

\section{3) Indeks Kesukaran Soal}

Indeks kesukaran butir-butir soal ditentukan dengan rumus sebagai berikut:

$$
P=\frac{B}{J S}
$$

Keterangan:

$\mathrm{B}=$ Banyaknya siswa yang menjawab soal tersebut dengan

JS = Jumlah seluruh siswa peserta tes

$\mathrm{P} \quad=$ Indeks kesukaran

Nilai $\mathrm{P}$ yang diperoleh selanjutnya dikonversikan menurut klasifikasi indeks kesukaran sebagai berikut:

$0.00<\mathrm{IK} \leq 0.30$ : (Soal sukar)

$0.31<\mathrm{IK} \leq 0.70$ : (Soal sedang)

$0.71<\mathrm{IK} \leq 1.00: \quad$ (Soal mudah)

(Arikunto, 2006).

\section{4) Daya Beda Soal}

Daya beda butir-butir soal ditentukan dengan rumus sebagai berikut:

$$
D=\frac{B A}{J A}-\frac{B B}{J B}
$$

\section{Keterangan:}

$\mathrm{BA}=$ Banyaknya peserta kelompok atas yang menjawab sc $\mathrm{BB}=$ Banyaknya peserta kelompok bawah yang menjawal

$\mathrm{JA}=$ Banyaknya peserta kelompok atas

$\mathrm{JB}=$ Banyaknya peserta kelompok bawah

$\mathrm{D}=$ Daya pembeda 
Karena jumlah sampel kurang dari 100 orang maka penentuan kelompok atas dan kelompok bawah dilakukan dengan cara mengurutkan siswa dari skor tertinggi hingga terendah kemudian membagi siswa menjadi 2 kelompok sama besar. Nilai D yang diperoleh selanjutnya dikonversikan menurut klasifikasi daya beda soal (Arikunto, 2006) sebagai berikut:
$\mathrm{D}=$ butir soal yang mempunyai nilai negatif sebaiknya dibuang saja.
$\mathrm{D}=0,00-0,20$ : Kurang
$\mathrm{D}=0,21-0,40 \quad:$ Cukup
$\mathrm{D}=0,41-0,70:$ Baik
$\mathrm{D}=0,71-1,00 \quad$ : Baik Sekali

\section{Revisi Perangkat}

Revisi perangkat dilakukan terhadap hasil yang diperoleh dari draf hasil uji kelompok terbatas sehingga tahap ini merupakan revisi tahap akhir dan hasilnya merupakan perangkat baku yang selanjutnya dilakukan evaluasi sumatif.

\section{Evaluasi Sumatif terhadap Efektifitas}

\section{Perangkat}

Pada tahap ini dilakukan pengujian perangkat pada kelas yang menerapkan Tabel 2. Hasil Uji Validasi Ahli model pembelajran KOSAJI dengan menyusun instrumen tes hasil belajar yang disesuaikan berdasarkan indikator pembelajaran untuk mengetahui efektifitas perangkat yang dikembangkan. Skenario pelaksanaan evaluasi sumatif adalah uji awal (pretes), kegiatan pembelajaran kooperatif tipe KOSAJI, dan uji akhir (postes). Rancangan ujicoba yang digunakan dalam pengembangan ini adalah D one group pretest-postest design.

\section{HASIL DAN PEMBAHASAN}

Penelitian ini mengembangkan sebuah model pembelajaran baru yaitu model pembelajaran kooperatif tipe KOSAJI beserta perangkat yang terdiri atas RPP, LKS, angket sikap siswa terhadap fisika dan tes hasil belajar kognitif siswa.

\section{Hasil Uji Validasi Ahli}

Hasil penilaian uji validasi ahli pada semua perangkat penelitian termasuk kategori sangat layak digunakan dengan nilai rerata $94,99 \%$ seperti yang terlihat pada Tabel 2.

\begin{tabular}{clcc}
\hline No & \multicolumn{1}{c}{ Perangkat Penelitian } & Skor Rata-rata & Keterangan \\
\hline $\mathbf{1}$ & Model Pembelajaran KOSAJI & $91,67 \%$ & Sangat layak digunakan \\
$\mathbf{2}$ & RPP KOSAJI & $95,24 \%$ & Sangat layak digunakan \\
$\mathbf{3}$ & Angket Sikap terhadap Fisika & $97,22 \%$ & Sangat layak digunakan \\
$\mathbf{4}$ & Tes Hasil Belajar Kognitif & $95,00 \%$ & Sangat layak digunakan \\
\hline
\end{tabular}




\begin{tabular}{ccclc}
\hline No & Perangkat Penelitian & Skor Rata-rata & \multicolumn{2}{c}{ Keterangan } \\
\hline $\mathbf{5}$ & Lembar Kerja Siswa & $95,83 \%$ & \multicolumn{2}{c}{ Sangat layak digunakan } \\
& \multirow{2}{*}{ Rata-rata } & $\mathbf{9 4 , 9 9 \%}$ & Sangat & layak \\
& & & digunakan & \\
\hline
\end{tabular}

Hasil validasi ahli menafsirkan secara umum model pembelajaran KOSAJI dan perangkat pembelajaran yang telah dibuat siap untuk diimplementasikan pada uji kelompok kecil. Beberapa masukan yang penting dalam uji validasi ahli ini berupa langkah-langkah pembelajaran pada model KOSAJI yang tertuang dalam RPP belum nampak perbedaannya dengan tipe STAD maupun Jigsaw. Berdasarkan Saran tersebut maka dilakukan perbaikan pada model pembelajaran KOSAJI dan RPP KOSAJI.

\section{Hasil Uji Kelompok Kecil}

Proses pembelajaran berlangsung dengan baik walaupun terdapat kekurangan. Model pembelajaran KOSAJI, RPP KOSAJI, dan LKS sebagian ada yang direvisi. Siswa dan guru memberi respon setuju terhadap implementasi model pembelajaran KOSAJI di dalam kelas. Berdasarkan hasil observasi keterlaksanaan RPP pun pada tahap ini sudah berjelan dengan baik. Kelemahan yang terlihat dengan pembelajaran tipe KOSAJI pada saat uji kelompok kecil adalah membutuhkan waktu yang cukup lama. Namun hal ini bisa diatasi dengan menyediakan lembar kegiatan siswa (LKS) yang ringkas dan terarah tanpa mengurangi substansi yang terkandung pada indikator dan tujuan pembelajaran sehingga siswa dapat bekerja secara efektif dan efisien.

\section{Hasil Uji Kelompok Terbatas}

Proses pembelajaran berlangsung dengan sangat baik. Model pembelajaran KOSAJI, RPP KOSAJI, dan LKS tidak ada yang direvisi. Tes hasil belajar kognitif diujicoba untuk mengetahui validitas, reliabilitas, tingkat kesukaran dan daya beda. Hasil ujicoba menunjukkan bahwa tes hasil belajar kognitif valid dan reliabel. Semua perangkat layak untuk diimplementasikan pada skala luas/sumatif. Siswa dan guru merespon sangat setuju terhadap implementasi model pembelajaran kooperatif tipe KOSAJI.

\section{Evaluasi Sumatif}

Penerapan model pembelajaran kooperatif tipe KOSAJI pada pembelajaran fisika efektif untuk meningkatkan hasil belajar kognitif siswa. Hal ini dapat dilihat dari rerata peningkatan hasil belajar kognitif siswa berdasarkan hasil pretes dan 
postes (Tabel 3). Hasil belajar kognitif siswa meningkat sebesar 41,93\%.

Tabel 3. Data Pretes Hasil Belajar Kognitif Model Pembelajaran Kosaji atau pemahaman tentang subyek yang diteliti. Penelitian pengembangan yang dimaksud dalam penelitian ini adalah untuk mengembangkan sebuah model pembelajaran baru yaitu model

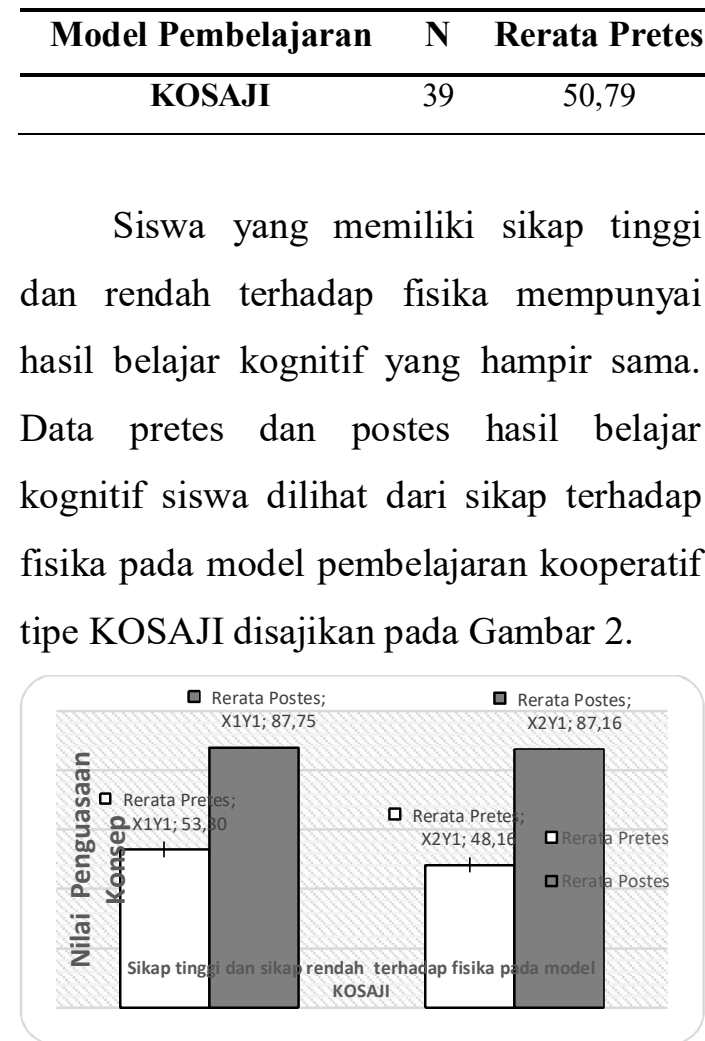

Gambar 2. Rerata sikap fisika siswa terhadap hasil belajar kognitif

Keterangan:

$\mathbf{x}_{1} \mathbf{y}_{1}$ : Responden yang memiliki sikap tinggi terhadap fisika dengan strategi KOSAJI

$\mathbf{x}_{2} \mathbf{y}_{1}$ : Responden yang memiliki sikap rendah terhadap fisika dengan startegi KOSAJI

Penelitian dan pengembangan didefinisikan sebagai studi sistematis terhadap pengetahuan ilmiah yang lengkap
S. DrembelRjerata Postdsoopesatîfev KOSAJI 7,7(kolaborasi8744AD dan 3b7GSAW) pada pembelajaran fisika yang valid, praktis dan efektif. Model penelitian pengembangan yang digunakan mengacu pada model pengembangan Dick \& Carey (2009).

Paradigma penelitian pengembangan menurut Visscher-Voerman (1999) terbagi menjadi 4 yaitu: paradigma instrumental (instrumental paradigm), paradigma komunikatif (communicative paradigm), paradigma pragmatis (pragmatic paradigm) dan paradigma artistik (artistic paradigm). Paradigma instrumental dicirikan dengan planning-by-objective, yakni rencana yang didasarkan pada tujuan. Analisis kebutuhan dan masalah dilakukan di awal proses pengembangan dan rumusan tujuan merupakan pusat dari model. Paradigma komunikatif ditentukan oleh keterlibatan orang-orang dalam penelitian. Paradigma pragmatis ditentukan oleh lingkungan sebagai tempat untuk implementasi produk dan penggunaannya. Paradigma artistik berkaitan dengan realitas sosial.

Penelitian pengembangan model pembelajaran kooperatif tipe KOSAJI memenuhi paradigma penelitian pengembangan seperti yang dikemukakan 
oleh Visscher-Voerman. Pada penelitian ini dilakukan analisis kebutuhan untuk menentukan tujuan pembelajaran di awal penelitian. Langkah ini bertujuan untuk mengetahui sasaran pembelajaran yang ingin dicapai. Secara spesifik, langkah ini dimaksudkan untuk mengetahui tujuan orientasi pembelajaran dan mengetahui tujuan pendukung yang memudahkan pencapaian tujuan orientasi tersebut. Adanya aktivitas kegiatan sosial antar subyek yaitu keterlibatan guru dan siswa dalam proses pembelajaran memberikan sebuah pencapaian dan kesimpulan yang sama. Adanya implementasi produk dan penggunaannya merupakan bagian utama dari proses. Keberhasilan pengembangan model pembelajaran kooperatif tercermin dari peningkatan hasil belajar kognitif siswa selama proses pembelajaran berlangsung.

Model pembelajaran kooperatif KOSAJI dalam penelitian ini memadukan sintaks pembelajaran kooperatif STAD dan Jigsaw. Siswa dibagi ke dalam kelompokkelompok kecil agar dapat saling membantu memahami materi pelajaran dan menyelesaikan tugas.

Model pembelajaran kooperatif tipe KOSAJI memfasilitasi siswa dalam kelompok belajar secara kolaboratif dengan mengikuti sintaks kombinasi STAD dengan Jigsaw. Siswa-siswa yang mengikuti model pembelajaran ini tidak hanya mendapatkan pengetahuan dari presentasi guru di kelas sebagaimana yang ada dalam sintak pembelajaran kooperatif tipe STAD, namun mereka juga mengemban tugas untuk menguasai materi yang dilimpahkan pada saat mereka sebagai anggota kelompok ahli sebagaimana pada tipe Jigsaw. Setiap siswa dituntut untuk menguasai materi tersebut sebelum mereka kembali ke kelompok asal. Setiap siswa pun akan mendapatkan pengetahuan dari anggota ahli lainnya sehingga pengetahuan yang mereka dapatkan menjadi utuh. Berdasarkan kombinasi ini, komunikasi dan kerjasama antar siswa dalam pembelajaran kooperatif tipe KOSAJI lebih banyak mereka lakukan baik bersama guru maupun antar siswa. Secara tidak langsung hal ini berdampak pada pengetahuan yang mereka peroleh lebih bermakna karena lebih sering diulang dibandingkan hanya menggunakan pembelajaran kooperatif tipe STAD maupun Jigsaw saja.

Seperti yang dijelaskan oleh Slavin (2011), berdasarkan teori siswa akan lebih mudah menemukan dan memahami konsep yang sulit jika mereka mendiskusikan konsep tersebut dengan teman sebayanya. Strategi pembelajaran kooperatif tidak hanya berimplikasi pada hasil belajar tersedia bagi semua siswa, tetapi juga mengakibatkan proses pemikiran siswa 
lain tersedia bagi semua orang. Belajar secara kooperatif secara tidak langsung akan memberikan pembelajaran kepada siswa cara teman-teman sejawatnya berhasil menyelesaikan masalah dalam satu kelompok melalui pendekatan mereka.

Sikap siswa terhadap fisika merupakan sejumlah informasi yang dimiliki oleh siswa terkait dengan pembelajaran fisika itu sendiri. Secara umum sikap siswa terhadap fisika berguna untuk mengetahui sejauh mana sikap siswa terhadap pelajaran fisika sebelum mengikuti proses pembelajaran. Siswa yang memiliki sikap yang tinggi memiliki kecenderungan meraih hasil belajar kognitif yang tinggi dan sebaliknya. Hasil ini sesuai dengan temuan Arizona (2013) yang membuktikan ada korelasi yang signifikan antara sikap dengan hasil belajar kognitif siswa. Hasil penelitian tersebut tidak sejalan dengan temuan pada penelitian ini. siswa yang memiliki sikap tinggi memperoleh nilai hasil belajar kognitif hampir sama dengan siswa yang memiliki sikap rendah terhadap fisika. Temuan ini menunjukkan bahwa model pembelajaran kooperatif tipe KOSAJI efektif meningkatkan hasil belajar kognitif siswa tanpa menghiraukan sikap siswa terhadap fisika. Model pembelajaran kooperatif tipe KOSAJI cocok untuk diterapkan pada siswa yang memiliki sikap tinggi dan rendah pada fisika. Bukti empirik yang menunjukkan hal ini adalah rerata hasil belajar kognitif kedua kelompok siswa hampir sama. Hal ini menjadi keunggulan tersendiri dari model pembelajaran kooperatif tipe KOSAJI.

\section{KESIMPULAN}

Kesimpulan berdasarkan hasil penelitian adalah pengembangan model pembelajaran kooperatif tipe KOSAJI pada pembelajaran fisika terbukti valid, praktis, dan efektif. Melalui penggunaan model pembelajaran KOSAJI diharapkan guru dan siswa dapat bekerjasama untuk mewujudkan kondisi belajar yang menyenangkan. Bagi para peneliti lanjutan, dapat mengembangkan penelitian serupa dengan pokok bahasan dan sampel yang berbeda. Selain itu perlu digunakan metode kualitatif untuk mengungkapkan secara mendalam tentang kelebihan dan kekurangan dari model pembelajaran KOSAJI, sehingga dapat meningkatkan kualitas pembelajaran fisika.

\section{DAFTAR PUSTAKA}

Arikunto, S. 2006. Dasar-Dasar Evaluasi Pendidikan. Jakarta: Bumi Aksara.

Arizona, K. 2013. Pengaruh Media Tiga Dimensi Kemagnetan Berbasis Inkuiri melalui Strategi Koopertif terhadap Kecakapan Sosial, Sikap Ilmiah dan Hasil Belajar Kognitif Fisika Siswa Kelas $\quad X$. Tesis S2. Universitas Mataram. 
Dick, Walter, Lou Carey, dan James O. Carey, 2009. The Systematic Design of Instruction, Seventh Edition. New Jersey Columbus, Ohio: Pearson.

Ibrahim, M., Rachmadiati, F., Nur, M. \& Ismono. 2000. Pembelajaran Kooperatif. Pusat Sains dan Matematika Sekolah. Program Pascasarjana UNESA. Surabaya: University Press.

Nur, M., dan Wikandari, P.R. 2000. Pengajaran Berpusat kepada Siswa dan Pendekatan Konstruktivis dalam Pengajaran. Pusat Studi Matematika dan IPA Sekolah UNESA. Surabaya: University Press

Riduwan. 2010. Metode dan Teknik Menyusun Tesis. Jakarta: Alfabeta.

Sanjaya, W. 2011. Perencanaan dan Desain Sistem Pembelajaran. Jakarta: Kencana Prenada Media Group.

Slavin, R. E. 2011. Psikologi Pendidikan Teori dan Praktik Jilid II Edisi Kesembilan. Penerjemah Marianto Samosir. Jakarta: Indeks.
Sugiyono. 2011. Statistika untuk Penelitian. Bandung: Alfabeta.

Sukiman, M. S. 2010. Efektivitas Penerapan Model Pembelajaran Sains Berbasis Inkuiri melalui Strategi Kooperatif terhadap Perkembangan Sikap Ilmiah dan Minat serta Hasil Belajar Biologi Siswa SMPN 2 Mataram. Tesis S2. Universitas Mataram.

Vissher-Voerman, Gustafson, Plomp. 1999. Educational Design and Development: An Overview of Pradigms. Dalam Pomp, T; Nieveen, N; Gustafson, K; Branch, R.M; dan Van den Akker, J. (eds). Design Approaches and Tools in Education 